\title{
Revisiting Boronate/Diol Complexation as a Double Stimulus-Responsive Bioconjugation
}

DOI:

10.1021/acs.bioconjchem.7b00080

\section{Document Version}

Accepted author manuscript

Link to publication record in Manchester Research Explorer

\section{Citation for published version (APA):}

Gennari, A., Gujral, C., Hohn, E., Lallana-Ozores, E., Cellesi, F., \& Tirelli, N. (2017). Revisiting Boronate/Diol Complexation as a Double Stimulus-Responsive Bioconjugation. Bioconjugate Chemistry, 28(5), 1391-1402. https://doi.org/10.1021/acs.bioconjchem.7b00080

\section{Published in:}

Bioconjugate Chemistry

\section{Citing this paper}

Please note that where the full-text provided on Manchester Research Explorer is the Author Accepted Manuscript or Proof version this may differ from the final Published version. If citing, it is advised that you check and use the publisher's definitive version.

\section{General rights}

Copyright and moral rights for the publications made accessible in the Research Explorer are retained by the authors and/or other copyright owners and it is a condition of accessing publications that users recognise and abide by the legal requirements associated with these rights.

\section{Takedown policy}

If you believe that this document breaches copyright please refer to the University of Manchester's Takedown Procedures [http://man.ac.uk/04Y6Bo] or contact uml.scholarlycommunications@manchester.ac.uk providing relevant details, so we can investigate your claim.

\section{OPEN ACCESS}




\title{
Revisiting Boronate/Diol Complexation as a Double Stimulus- Responsive Bioconjugation
}

\author{
Arianna Gennari ${ }^{1}$, Chirag Gujral ${ }^{1}$, Erwin Hohn ${ }^{1 \S \S}$, Enrique Lallana ${ }^{1}$, Francesco Cellesi $^{2}$, \\ Nicola Tirelli $i^{*}$
}

\footnotetext{
${ }^{1}$ NorthWest Centre of Advanced Drug Delivery (NoWCADD), School of Health Sciences, University of Manchester, Oxford Road, Manchester, M13 9PT, United Kingdom

2 1. Dipartimento di Chimica, Materiali ed Ingegneria Chimica "G. Natta". Politecnico di Milano, Via Mancinelli 7, 20131 Milan, Italy 2. Fondazione CEN - European Centre forNanomedicine, Piazza Leonardo da Vinci 32, 20133 Milan, Italy

^Current address: School of Parmacy, Queen’s University Belfast, 97 Lisburn Road, BT7 1NN, Belfast, United Kingdom

$\S$ Current address: Sandoz Biopharmaceuticals and Oncology Injectables, Lehenau 10a, 5325 Plainfeld, Austria
}

* corresponding author

Nicola.tirelli@manchester.ac.uk 


\begin{abstract}
This study presents a quantitative assessment of the complexation between boronic acids and diols as a reversible and double-stimulus (oxidation and acidification)-responsive bioconjugation reaction. Firstly, by using a competition assay, we have evaluated the equilibrium constants (water, $\mathrm{pH}$ 7.4) of 34 boronate/diol pairs, using diols of both aliphatic and aromatic (catechols) nature; in general catechols were characterized by constants three order of magnitude higher than those of aliphatic diols.

Secondly, we have demonstrated that successful complexation with diols generated in situ via enzymatic reactions, and the boronate complexation was also employed to calculate the MichaelisMenten parameters for two catechol-producing reactions: the demethylation of 3-methoxytyramine and the 2-hydroxylation of estradiol, respectively mediated by P4502D6 and P4501A2.

Thirdly, we have prepared phenylboronic acid-functionalized hyaluronic acid (HA) and demonstrated the $\mathrm{pH}$ and $\mathrm{H}_{2} \mathrm{O}_{2}$-responsive character of the adducts that it formed with Alizarin Red S (ARS) used as a model catechol.

The versatility and selectivity of the complexation and the mild character of the chemical species involved make therefore the boronate/catechol reaction an interesting candidate for bioconjugation purposes.
\end{abstract}




\section{INTRODUCTION}

The reaction between boronates and diols in aqueous solution is quantitative, selective and orthogonal to the reactivity of a majority of biologically relevant functional groups ${ }^{1,2}$, thus fulfilling the typical requirements of a bioconjugation reaction ${ }^{3}$. Indeed, the boronate/diol complexation has been used to decorate the surface of living cells (their glycocalyx) with synthetic polymers ${ }^{4,5}$, to selectively recognize saccharides in biological fluids ${ }^{6}$, and for protein immobilization ${ }^{7,8}$. The complexation between boronate-functionalized polymers and aliphatic ${ }^{9}$ or aromatic $^{10}$ polyols has also been employed to prepare cross-linked colloids, or hydrogels that acquire self-healing properties from the reversibility of the reaction ${ }^{11}$. A recent review covering the various applications of boronic acidcontaining polymers (and their diol complexes) has been recently published by Sumerlin ${ }^{12}$ and provides an up-to-date overview of the field. We are specifically interested in applying this versatile bioconjugation to hyaluronic acid (HA, Scheme 1). HA is a glycosaminoglycan found in virtually all extracellular matrices ${ }^{13-17}$, with a broad spectrum of FDA-approved applications as a biomaterial ${ }^{18,19}$. HA conjugation with bioactive molecules is appealing, because it combines the biocompatibility, degradability and non-immunogenicity of HA, the improvement in solubility and half-life of the coupled (pro)drug ${ }^{20,21}$, and the possibility to target HA receptors such as CD44, which is overexpressed in several pathological conditions ${ }^{22}$ (e.g. tumor progression ${ }^{23-26}$ or inflammatory disorders ${ }^{27,28}$ ). Following this approach, we have recently used boronic acid-bearing HA derivatives for the reversible bioconjugation and delivery (in a nanoparticle form) of a biocidal polyphenol, tannic $\operatorname{acid}^{29}$.

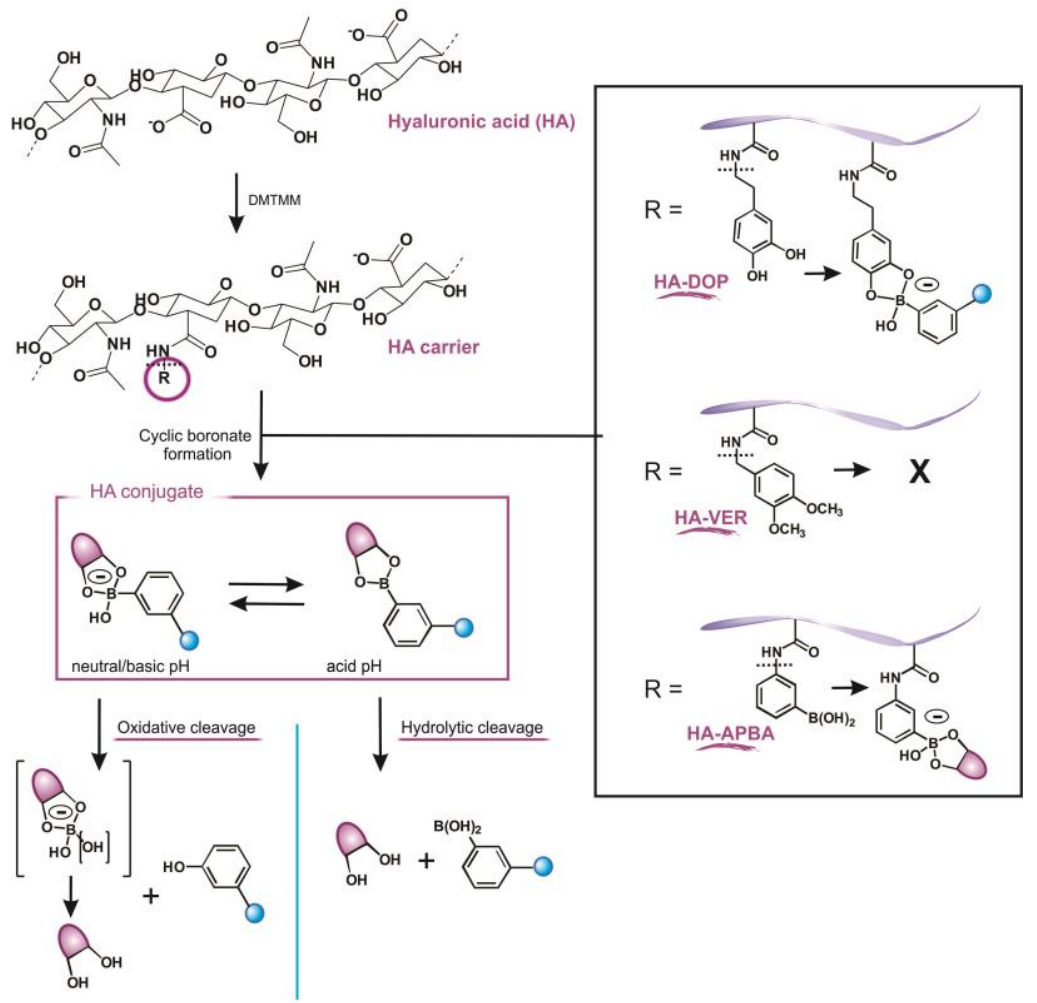

Scheme 1. HA structures were prepared via DMTMM-mediated amidation with dopamine (DOP), veratrylamine (VER: negative, non boronate-binding control) and 3-aminophenyl boronic acid (APBA). DOP and APBA derivatives can complex respectively boronate- and diol- containing molecules, and in both cases HA conjugates presenting cyclic boronic ester groups as side chains are produced. The latter bear a negative charge at neutral/basic $\mathrm{pH}$ due to quaternarization of boron by $\mathrm{OH}$ anions; at acid $\mathrm{pH}$, their neutralization decreases the complex stability and thus determines the release of payloads via hydrolytic cleavage and production of a diol and a boronate. As a second destabilization mechanism, the lability of the carbon-boron bond in an oxidizing environment releases a phenol and a cyclic borate, the latter eventually releasing a diol. 
Interestingly, boronic esters are also environmentally responsive groups, being cleavable under acidic and oxidizing conditions (bottom left in Scheme 1): A) B-O bonds have a markedly different hydrolytic stability when involving tri-coordinated boron atoms (at low $\mathrm{pH}$, easily hydrolyzable) or quaternarized e.g. by hydroxyl groups (at neutral or basic $\mathrm{pH}$, more stable against hydrolysis) ${ }^{30}$. This has often been exploited to release drugs at acidic $\mathrm{pH}^{10,31}$ or to design carriers that would disassemble under acidic condition allowing their cargo to be released ${ }^{10,32}$. B) C-B bonds can be easily cleaved by oxidants such as hydrogen peroxide ${ }^{33}$, a feature used in boron organic chemistry since the $50 \mathrm{~s}^{34-36}$ and more recently investigated as a tool to deliver payloads under oxidative conditions (e.g. sites of inflammation) $)^{37}$. Recent literature offers also examples of bioconjugates sensitive to the combination of acidic $\mathrm{pH}$ and reactive oxygen species (ROS), and used to image apoptotic phenomena ${ }^{38}$.

In order for the boronate/diol conjugation to have practical applications, the advantages of its stimulus responsiveness must be accompanied by a good stability in the absence of the stimuli. Therefore, the quantitative evaluation of boronic ester stability becomes critical; for example, its dependency on the diol $\mathrm{pKa}$ is well known ${ }^{39}$. Here, we have focused on the comparative evaluation of the binding strength $(\mathrm{pH}=7.4)$ of a library of diols (Scheme 2) when binding to 3-aminophenylboronic acid (APBA) as a low molecular weight ligand, as well as a functional side group in a macromolecular structure (HA). The diols encompass a number of different structures, including sugars, catechols with high (HA-dopamine and PEG-dopamine) and low molecular weight and negative controls (1,3 or methylated catechols). Some substrates were enzymatically generated in situ (dopamine, 2hydroxyestradiol) and/or solubilized thanks to a surfactant or a molecular host (quercetin, 2hydroxyestradiol).

From the analytical point of view, the most popular assay employed in similar studies is based on the fluorescence of Alizarin Red S (ARS, a low pKa antraquinonic catechol), whose emission markedly increases when complexed to a bor(on)ic acid. The affinity of a diol of interest and the bor(on)ic acid can be easily calculated through its competition with ARS and the correspondingly reduced emitted intensity $^{30,40}$. This approach, however, suffers of two drawbacks; first, the use of the BenesiHildebrand method, which for weak complexes (i.e. when the diol is a strong competitor such as a catechol) may produce large systematic errors ${ }^{41}$. Second, fluorescence readings can be seriously affected by scattering, which means that complex dispersions can be a challenge. In this paper, to overcome the aforementioned limitations, we present a method based on the ARS hypsochromic shifts: the absorption spectrum of ARS shifts from red to yellow after binding boronic acids, which has been often used to qualitatively assess the formation of boronic esters ${ }^{10,38,40}$. 


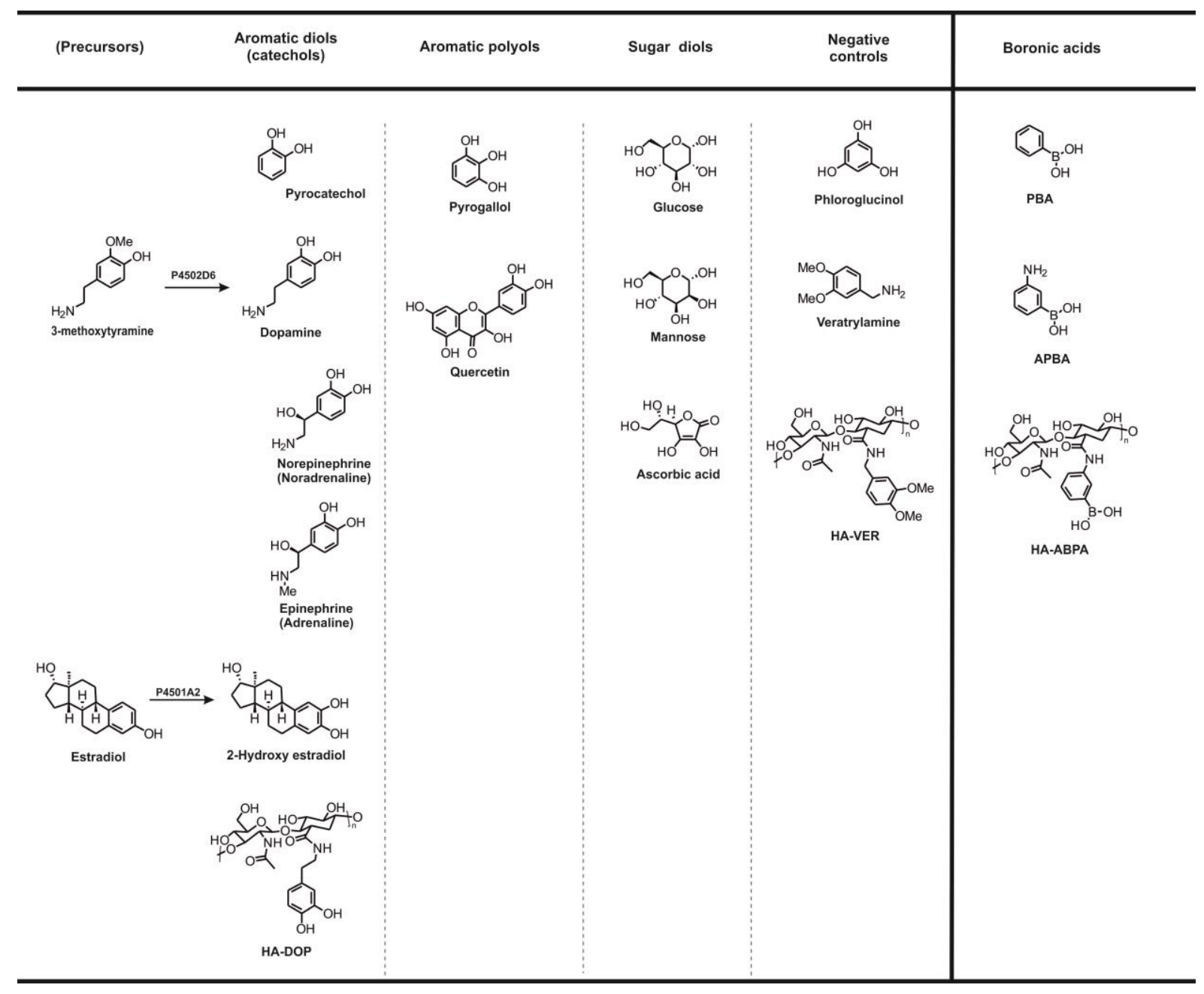

Scheme 2. Structures of diols (columns in the left and in the centre) and boronic acids (right column) used in this study. Dopamine was used in a free aromatic diol form, but was also generated in situ via enzymatic demethylation from 3methoxytyramine; a second aromatic diol was prepared in situ, i.e. -2-hydroxyestradiol obtained via enzymatic oxidation of estradiol in cyclodextrin suspension. As negative controls, we have used compounds cannot bind (strongly) to boronic acids either because of the non-vicinal position (phloroglucinol) or the methylation of $\mathrm{OH}$ groups.

\section{RESULTS AND DISCUSSION}

\section{Preparation of hyaluronic acid derivatives}

In this study we have prepared and employed HA derivatives bearing 16-19\% mol of functional residues, and with a weight average molecular weight in the range of $200-300 \mathrm{kDa}$ (from SECMALLS measurements; see Supporting Information, Section 1SI, Additional materials and methods). HA was functionalised with amine-containing compounds using 4-(4,6-dimethoxy-1,3,5-triazin-2-yl)4-methylmorpholinium chloride (DMTMM) as a water soluble activating agent (experimental procedure provided in the Supporting Information). DMTMM was preferred to the more popular $N$ (3-dimethylaminopropyl)- $N$-ethylcarbodiimide (EDC): the reaction product of the latter is both strongly hydrogen bonding and partially protonated at physiological $\mathrm{pH}$, and therefore difficult to remove from HA in a quantitative fashion. While the size of HA with low and medium molecular weight $\left(\overline{M_{w}}=51\right.$ and $210 \mathrm{kDa}$, respectively) did not show significant decrease following functionalization, degradation was observed when the starting material was high molecular weight HA (see Supporting Information, Table 1SI). The choice of the degree of derivatization was a compromise between high functionalization and retention of enzymatic degradability. Since 
mammalian hyaluronidases bind to HA utilizing its anionic carboxylic groups, with a binding region spanning at least a hexasaccharide sequence ${ }^{42}$ the introduction of groups bearing no negative charge may alter its degradability, as it happens for a number of HA derivatives such as the HYAFF family. ${ }^{43}$, ${ }^{44}$ However, although with a slower kinetics than the pristine HA, all the derivatives prepared in this study substantially maintained their enzymatic degradability (see Supporting Information, Figure 1SI A). The presence of boronic acid groups caused negligible cytotoxicity on two cellular models with IC50>1\% wt. for both L929 fibroblasts, J774.2 macrophages (see Supporting Information, Figure 1SI B); veratrylamine still caused relatively low toxicity, with IC50 values in the range $5-10 \mathrm{mg} / \mathrm{mL}$, but the free catechols of HA-DOP caused the IC50 to drop in the proximity to $1-2 \mathrm{mg} / \mathrm{mL}$ in both cell lines.

\section{Boronic acid/diol equilibrium constants through a spectral shift method}

The UV-Vis spectrum of ARS largely changes upon complexation with boronic acids: in water the wavelength of the absorption maximum of ARS shifts from $510 \mathrm{~nm}$ in the free state to $460 \mathrm{~nm}$ in the complexed form (Figure 1A); this red-to-yellow colour change is accompanied by the development of fluorescence associated the boronic ester and the two phenomena have been extensively reported in the literature. ${ }^{30}$ Both fluorescence and spectral shifts are associated to the formation of the complex, thus either of them can provide the boronate-bound / free ARS molar ratio, allowing to calculate the corresponding equilibrium constants (see experimental section for a detailed description).

For a comparison of the two techniques, we have used the complexation of ARS to two model compounds: phenyl boronic acid (PBA) and 3-aminophenyl boronic acid (APBA). PBA allows a comparison to literature data, whereas APBA is a model for more functional boronic acids. From fluorescence, we have obtained $K_{1}^{\text {fluor }}(P B A)=1648 \pm 97 \mathrm{M}^{-1}$, a value very similar to what obtained by Wang ${ }^{30}$ using the same method $\left(1300 \mathrm{M}^{-1}\right)$, whereas the spectral shift method provided $K_{1}^{\text {shift }}(P B A)=2357 \pm 172 \mathrm{M}^{-1}$. For the second equilibrium, we found $K_{1}^{\text {fluor }}(A P B A)=1349 \pm 73$ $\mathrm{M}^{-1}$ and $K_{1}^{\text {shift }}(A P B A)=2465 \pm 132 \mathrm{M}^{-1}$. The spectral shift method therefore provided higher equilibrium constants, as a graphical comparison may also suggest (Figure 1B: the empty circles reach a plateau before the black squares). The difference between the two methods possibly stems from the higher sensitivity of fluorescence to additional factors, such as aggregation or scattering from the suspension; in fact, in some cases the fluorescence signal showed a significant decrease in intensity with time (see Supporting Information, Figure 3SI), which is possibly due to self-quenching caused by the increased proximity of fluorophores in aggregates. A third technique ( ${ }^{1} \mathrm{H}$ NMR) was also employed to calculate the binding constant between ARS and PBA or APBA (see Supporting Information, additional material and methods and Figure 4SI). The equilibrium constants in this case were slightly higher $\left(K_{1}^{N M R}(P B A)=3100 \mathrm{M}^{-1}\right.$ and $\left.K_{1}^{N M R}(A P B A)=3600 \mathrm{M}^{-1}\right)$ than those calculated from the spectral shift further confirming that probably affinities measured by fluorescence are underestimated.

Due to its better stability, we have then employed the ARS spectral shifts for all further complexation studies. In particular, we have used the ARS as a reporter in competitive equilibria with other diols (Figure 1C, see Scheme 2 for the chemical structures of all diols used), estimating the binding constants of these diols to APBA and HA-APBA (Table 1). The reliability of the method was confirmed by using three negative controls: the dimethylated catechol of veratrylamine, and the allmeta aromatic hydroxy groups of phloroglucinol did not show any appreciable competition with ARS. In accordance to literature, the affinity for boronates of sugar diols was markedly lower than that of aromatic diols ${ }^{30}$; this is due to a combination of lower acidity (hence negligible deprotonation at physiological $\mathrm{pH}$ ) and a less favourable conformation of the vicinal $\mathrm{OH}$ groups. The latter point 
explains why mannose - a cis diol - binds more strongly than glucose, while both factors rationalize the higher binding of ascorbic acid.

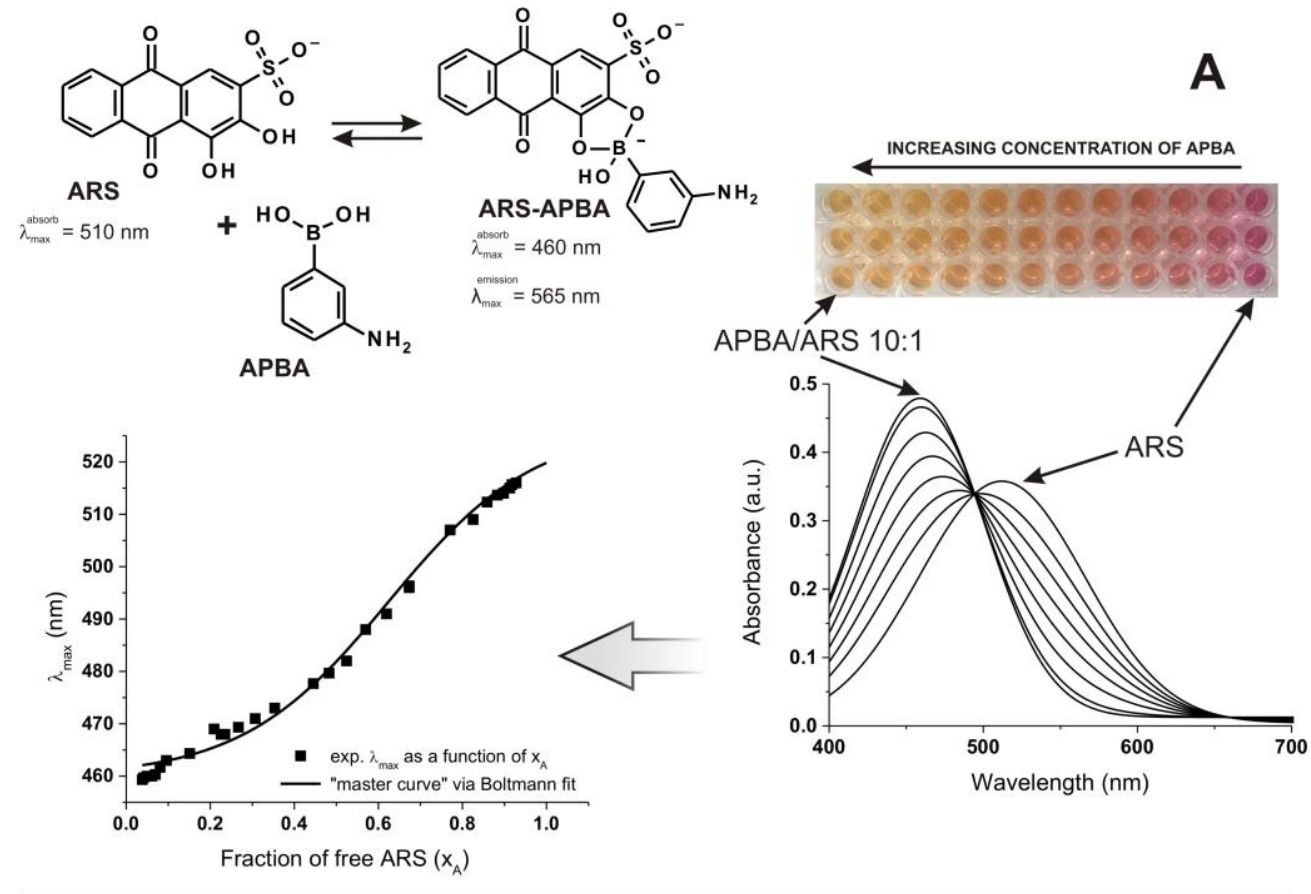

B
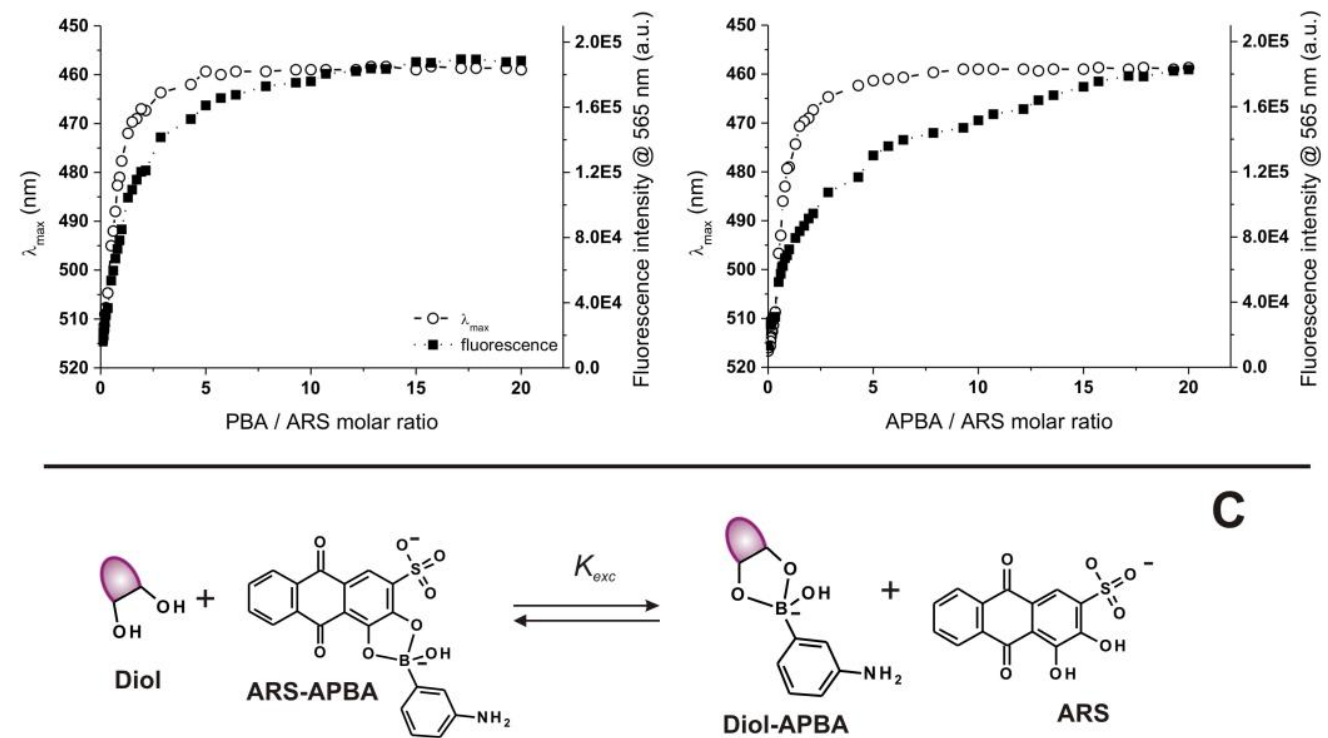

C

Figure 1. A: the Vis spectra of $0.15 \mathrm{mM}$ ARS in PBS show a strong (up to $50 \mathrm{~nm}$ ) hypsochromic shift with increasing content of the boronic acid APBA (graph on the right); the clear isosbestic point at $490 \mathrm{~nm}$ ensures the presence of only two species in the equilibrium: ARS and ARS-APBA. The $\lambda_{\max }$ of the curves obtained as linear combinations of the spectra of ARS and of the ARS/APBA complex (see Supporting Information, Figure 2SI) has a sigmoidal dependence on $x_{A}$ that can be fitted with a Boltzmann equation, generating a 'master curve' that has an excellent agreement with the experimental data (graph on the left). $\boldsymbol{B}$ : the shift in the absorption maximum and the fluorescence intensity provide comparable results, but in some cases fluorescence data are affected by additional phenomena. For example, while the two methods provide identical results for the complexation of ARS with phenyl boronic acid (PBA), the use of APBA (featuring an additional $\mathrm{NH}_{2}$ group) causes a progressive increase of the fluorescence, possibly related to scattering; additionally, when using HA-APBA, the fluorescence intensity exhibited a clear time dependency (see Supporting Information, Figure 3SI). C: sketch of the 
competitive equilibria used to calculate the affinity of diols to APBA (or HA-APBA); considering that $K_{e x c}=\frac{K_{d i o l}}{K_{A R S}}$, from the knowledge of $K_{A R S}$, [ARS] and [ARS-APBA] it is possible to obtain $K_{\text {diol }}$ (Table 1).

Table 1. Equilibrium constants for the complexation of diols with APBA and HA-APBA at pH 7.4 in 0.1 M PBS buffer. SD are calculated over $n=3$.

\begin{tabular}{|c|c|c|c|c|c|}
\hline \multicolumn{3}{|c|}{ Diol } & \multirow{2}{*}{$\begin{array}{c}\mathrm{K}[\mathbf{A P B A}] \\
\left(\mathrm{M}^{-1}\right)\end{array}$} & \multirow{2}{*}{$\begin{array}{c}\mathrm{K}[\mathbf{H A}-\mathbf{A P B A}]^{\mathrm{a}} \\
\left(\mathbf{M}^{-1}\right)\end{array}$} & \multirow{2}{*}{$\underset{\mathrm{pH}^{\mathrm{b}}}{\text { optimal }}$} \\
\hline Class & Name & $\mathrm{pK}_{\mathrm{a}}$ & & & \\
\hline $\begin{array}{l}\text { Positive } \\
\text { control }\end{array}$ & ARS & 4 & $2465 \pm 132$ & $2550 \pm 150^{c}$ & 6.5 \\
\hline \multirow{3}{*}{ 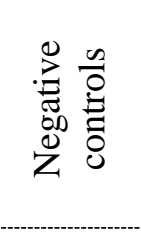 } & Phloroglucinol & $8.5^{45}$ & 0 & 0 & 8.7 \\
\hline & Veratrylamine & $=$ & 0 & 0 & $=$ \\
\hline & HA-VER & $=$ & 0 & 0 & $=$ \\
\hline \multirow{6}{*}{ 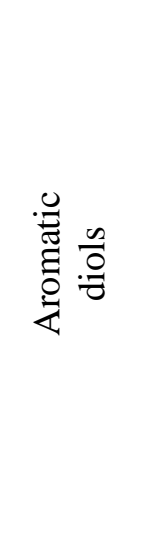 } & Pyrocatechol & $8.6^{46}$ & $1490 \pm 70$ & $1844 \pm 110$ & 8.8 \\
\hline & Dopamine & $8.9^{47}$ & $1555 \pm 66$ & $1955 \pm 117$ & 8.9 \\
\hline & $\begin{array}{c}\text { Dopamine from } \\
\text { 3-methoxytyramine }\end{array}$ & $8.9^{47}$ & $1550 \pm 73$ & $1839 \pm 110$ & 8.9 \\
\hline & Epinephrine & $8.6^{48}$ & $1445 \pm 65$ & $1910 \pm 114$ & 8.7 \\
\hline & Norepinephrine & $8.6^{49}$ & $1545 \pm 66$ & $1969 \pm 118$ & 8.8 \\
\hline & $\begin{array}{l}\text { 2-hydroxy estradiol } \\
\text { from estradiol }\end{array}$ & $9.7^{\mathrm{d}}$ & $955 \pm 38^{\mathrm{e}}$ & $1061 \pm 67^{\mathrm{e}}$ & 9.4 \\
\hline \multirow{2}{*}{ 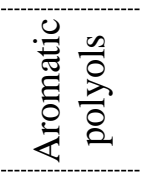 } & Pyrogallol & $9.1^{50}$ & $1796 \pm 78^{\mathrm{f}}$ & $2325 \pm 140^{f}$ & 9.0 \\
\hline & Quercetin & $7.6^{50}$ & $1240 \pm 98^{g}$ & $1312 \pm 115^{\mathrm{g}}$ & 8.3 \\
\hline \multirow{3}{*}{ 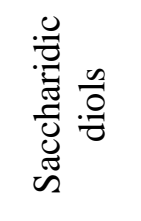 } & Mannose & $12.1^{51}$ & $6 \pm 1$ & $6 \pm 1$ & 10.5 \\
\hline & Glucose & $12.3^{51}$ & $4 \pm 1$ & $4 \pm 1$ & 10.6 \\
\hline & Ascorbic acid & $4.2^{52}$ & $6 \pm 1$ & $7 \pm 1$ & 6.5 \\
\hline \multirow{2}{*}{ 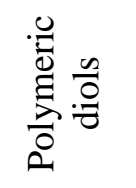 } & HA-DOP & $(8.9)^{h}$ & $1440 \pm 61$ & $1717 \pm 103$ & $(8.9)^{\mathrm{h}}$ \\
\hline & PEG-dopamine & $(8.9)^{\mathrm{h}}$ & $1025 \pm 42$ & $1432 \pm 86$ & $(8.9)^{\mathrm{h}}$ \\
\hline
\end{tabular}

\footnotetext{
${ }^{\mathrm{a}}$ The equilibrium constants were measured by using HA-APBA(1100).

${ }^{\mathrm{b}}$ The optimal $\mathrm{pH}$ was calculated according to Yan et al. ${ }^{53}$ as $p H_{\text {optimal }}=\left(p K_{a}\right.$ (boronic acid $)+p K_{a}($ diol $\left.) / 2\right)$. The $\mathrm{pK}_{\mathrm{a}}$ of HA-APBA is assumed to be in the region of 9, similarly to APBA.

${ }^{c}$ The values for the complexation of ARS with HA(235)-APBA or HA(35)-APBA are respectively $2605 \pm 332$ and $2525 \pm$ $213 \mathrm{M}^{-1}$.

d Predicted via the ChemAxon pKa calculator (http://www.chemaxon.com/products/calculator-plugins/propertypredictors/\#pka).

${ }^{\mathrm{e}}$ In the presence of sulfonated $\beta$-cyclodextrin to solubilise the steroid. The end point of the enzymatic reaction was used to calculate the value of the equilibrium constant, assuming complete conversion of estradiol.

${ }_{\mathrm{f}}^{\mathrm{f}}$ In the presence of TCEP to avoid pyrogallol oxidation.

${ }^{\mathrm{g}}$ In the presence of Tween 20 to solubilise quercetin.

${ }^{\mathrm{h}}$ Due to the structural similarity, we estimate the $\mathrm{pK}_{\mathrm{a}}$ of these catechols to be substantially analogous to that of dopamine.
} 
On the other hand, all aromatic diols and polyols exhibited a similar affinity to APBA or HA-APBA, indicating a negligible influence of the nature, size or polarity of the other parts of the molecule. The equilibrium constants for these compounds were lower than that of ARS, which is a likely consequence of their higher $\mathrm{pKa}$ (= lower chance of quaternarization of the boronate ester).

It is noticeable that the macromolecular nature of HA-APBA did not appear to have any detrimental influence: HA-APBA with $\overline{M_{w}}=50$ and $300 \mathrm{kDa}$ had indistinguishable affinity for ARS (resp. $2605 \pm$ 332 and $2525 \pm 213 \mathrm{M}^{-1}$ ). Further, the binding of any diol was slightly but consistently higher for the polymeric HA-APBA than for the low molecular weight APBA; this slight increase is likely to stem from an avidity effect (= local concentration of boronates being higher than the macroscopic one), which would also explain the higher binding strength recorded for HA-DOP vs. PEG-dopamine. It is, however, important to notice that the equilibrium constants recorded on macromolecular compounds are average values: the binding strength of HA-APBA with free boronates is likely much higher than that of the same polymer where the same groups are almost all bound to catechols.

\section{Enzyme-induced bioconjugation}

Catechols can be generated by a variety of enzymatic methods and we investigated whether these processes can be used for the in situ bioconjugation of the products. As examples, we have used two variants of cytochrome P450, CYP2D6 as a demethylase ${ }^{54}$ and CYP1A2 as a hydroxylase ${ }^{55}$, to respectively produce dopamine from 3-methoxytyramine ${ }^{56}$ and 2-hydroxyestradiol from estradiol ${ }^{57}$ (Figure 2). These two processes can act as general models for the conjugation of in situ generated catechols, respectively with a hydrophilic and a hydrophobic nature.

The constants for the dopamine - APBA/HA-APBA equilibria were measured previously and those obtained for enzymatically generated dopamine were indistinguishable (Table 1, compare the sixth and seventh entries), which confirmed both the efficiency in the demethylation of 3-methoxytyramine and the robustness of the analytical method. The conversion of estradiol into a catechol was performed in a more complex environment, since estradiol was solubilized in a sulphated $\beta$ cyclodextrin guest-host system. The constants that we recorded for the 2-hydroxyestradiol APBA/HA-APBA equilibria were significantly lower than those shown by all other catechols; we ascribe this to both the more difficult accessibility of the catechol in the guest-host complex and above all to the electrostatic repulsion between the anionic groups on the cyclodextrin and on ARS.

Most interestingly, the spectral shift method allowed also to follow the kinetics of the enzymatic reactions, by monitoring the ARS absorbance as a function of time (Figure 2A and 2B). By knowing the equilibrium constant of the catechol and under the assumption that the complexation is considerably quicker than the enzymatic conversions, it was then possible to estimate the kinetic parameters for both reactions (Table 2). For the production of dopamine, a direct comparison of our results with literature data is hardly possible, because this reaction has never been studied quantitatively; our data are broadly comparable to examples of CYP2D6-mediated demethylation of $o$-methylphenols, which however are largely variable (see Supporting information Table 2SI) possibly as a result of the large polymorphism of this enzyme ${ }^{58}$. The only noteworthy point is that our $K_{M}$ values are rather high, suggesting a lower affinity of the enzyme for a substrate with an $\mathrm{OH}$ vicinal to the target methoxy group. A more quantitative comparison would appear to be possible for the 2hydroxylation of estradiol, for which $K_{M}$ and the enzymatic clearance appear to be respectively in the proximity of $20 \mu \mathrm{M}$ and in the range $0.018-0.06 \mu \mathrm{L} /(\mathrm{pmol} \mathrm{P} 450 * \mathrm{~min}$ ) (see Supporting information Table 2SI; please note that the reactions are strongly NADPH-dependent and the $K_{M}$ vary considerably depending on the presence of the latter, see Supporting Information, Figure 6SI). We 
have observed a very comparable clearance value but a dramatically lower $K_{M}$; this can be attributed to the charge and steric hindrance of the estradiol/cyclodextrin complex, but literature values often refer to oversaturated solutions (up to $200 \mu \mathrm{M}$ with estradiol water solubility being $20 \mu \mathrm{M}^{59}$ ) where phase separation may lead to an overestimated affinity of CYP1A2 for estradiol.

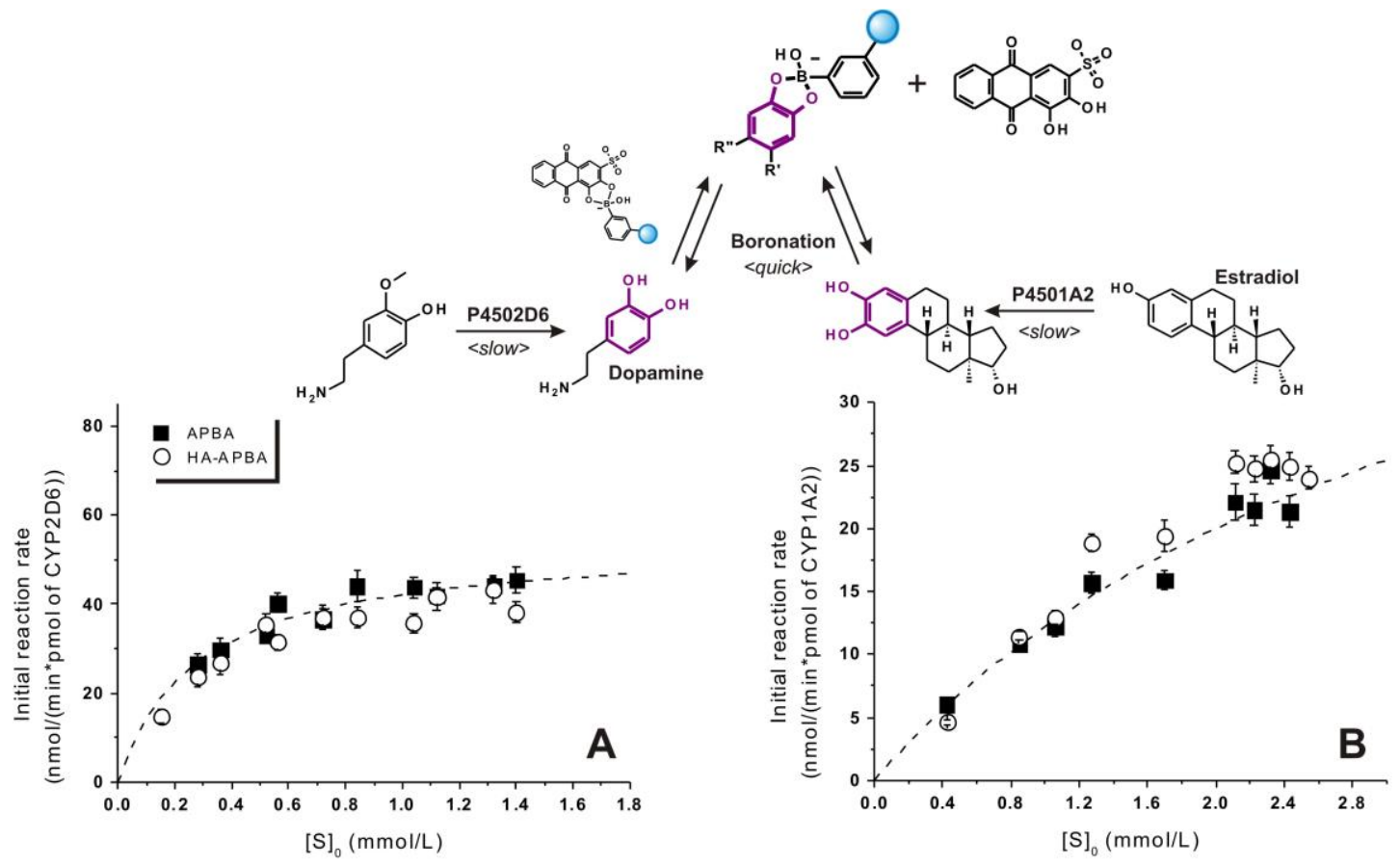

Figure 2. The one-pot conjugation through in situ enzymatic generation of catechols and binding to boronic derivatives can be monitored using ARS as an efficient reporter system that allows to extract information about enzymatic kinetics. The Michaelis-Menten plots in A and B are respectively obtained through the P450-mediated demethylation of 3methoxytyramine to dopamine $(\boldsymbol{A})$ and the hydroxylation of estradiol $(\boldsymbol{B})$.

Table 2. Kinetic parameters for the P4502D6-mediated demethylation of 3-methoxytyramine and for the P4501A2-mediated 2-hydroxylation of estradiol. (HA-)APBA complexation used as a reporter.

\begin{tabular}{|c|c|c|c|c|}
\hline Substrate & Reporter & $\begin{array}{c}\boldsymbol{K}_{M} \\
(\mu \mathrm{M})\end{array}$ & $\begin{array}{c}\boldsymbol{v}_{\max } \\
(\mathrm{pmol} /(\mathrm{pmol} \\
\mathrm{P} 450 * \min )) \\
\end{array}$ & $\begin{array}{l}\text { Hydrolase activity } \\
{\text { (CLint) })^{\mathbf{a}}}^{(\mu \mathrm{L} /(\mathrm{pmol} \mathrm{P} 450 / \mathrm{min}))}\end{array}$ \\
\hline \multirow{2}{*}{ 3-methoxytyramine } & APBA & $281 \pm 8$ & $49 \pm 4$ & 0.18 \\
\hline & HA-APBA & $285 \pm 6$ & $54 \pm 3$ & 0.19 \\
\hline \multirow{2}{*}{ Estradiol } & APBA & $3800 \pm 650$ & $65 \pm 13$ & 0.017 \\
\hline & HA-APBA & $3570 \pm 990$ & $56 \pm 11$ & 0.015 \\
\hline
\end{tabular}

\section{Release behaviour and double responsiveness of boronate/catechol conjugates}

Despite the relatively low values of the equilibrium constant at neutral $\mathrm{pH}$, the complexation strength of aliphatic diols with boronates is still sufficiently high to allow e.g. the determination of a variety of saccharidic structures ${ }^{60,61}$. As reported above, the complexation of boronate/catechol couples is orders 
of magnitude more stable than that of aliphatic diols, therefore in principle amenable to bioconjugation; nevertheless, the equilibrium constants are not very large (around $10^{3} \mathrm{M}^{-1}$ ), and they may not be able to guarantee stability against dilution, which is a common problem in the design of injectable pharmaceutical formulations. In this part of the work, we have focused on improving the stability of the structure through the use of a stoichiometric excess of boronates on the HA structure, i.e. by locally increasing the carrier avidity. Please note that, due to the higher local concentration of free boronates, the resulting binding of the catechols is considerably stronger than what could be assumed on the basis of the equilibrium constants presented in Table 1; while the latter were obtained using variable boronate/catechol ratios and therefore present an average binding strength, an excess of free boronates is expected to increase is significantly (see e.g. the difference between experimental data and theoretical values in Figure 3A).

The boronate/diol complexes are well known to reverse by acidification ${ }^{30}$, although in a fashion dependent on the diol pKa. Here, we have placed the solution of an HA-APBA/ARS conjugate at $\mathrm{pH}$ 7.4, 7.0, 6.0, 5.0 in dialysis bags, measuring the release of ARS in a 20-fold larger volume of fluid (thereby at least partially evaluating the effect of dilution) as a function of time. The equilibrium is apparently reached after 24 hours (Figure 3A), showing that at $\mathrm{pH} 7$ about $30 \%$ of the diol was released, therefore showing a relatively good stability of the complex; on the other hand, at acidic $\mathrm{pH}$ the decomplexation was quantitative; importantly, the release kinetics shows an initial burst followed by a slower release, but this profile is likely much affected by the transfer through the dialysis membrane, and the actual release may be considerably more rapid. Importantly, the overall trend observed was in agreement with the data already reported ${ }^{30}$ underline once more the little effect of the HA on the $\mathrm{pH}$-induced release phenomenon.

The oxidative cleavability of the boronate esters is based on cleavage of sp2 carbon-boron bond ${ }^{37}$, and correspondingly increasing amounts of 3-aminophenol were produced when a APBA/ARS adduct was incubated with increasing amounts of $\mathrm{H}_{2} \mathrm{O}_{2}$ (Figure 3B). It is noticeable that, although the oxidation of free catechols to orto-quinones is also possible, no trace of ARS quinone were found, thus suggesting that catechols may be released as oxidation-protected boric acid complexes. This is an important point to ensure the stability of in principle oxidation-sensitive drugs in an oxidizing (e.g. inflamed) biological environment.

Having proven the principle of the oxidative responsiveness, it is also important to note that this was not perfectly stoichiometric, and a certain excess of oxidant appeared necessary for a quantitative conversion of the complexes. For example, stoichiometric equivalence of $\mathrm{H}_{2} \mathrm{O}_{2}$ only corresponded to a $35 \%$ oxidation of the APBA/ARS, and higher excesses of oxidants were necessary for HAAPBA/ARS conjugates (50\% release with 10 equivalents). The apparently lower reactivity of the macromolecular complexes may actually stem from the presence of an excess of non-complexed boronic acids (to boost the carrier avidity) that are likely easier to oxidize. However, this event corresponds to the release of boric acid, not of the drug. 

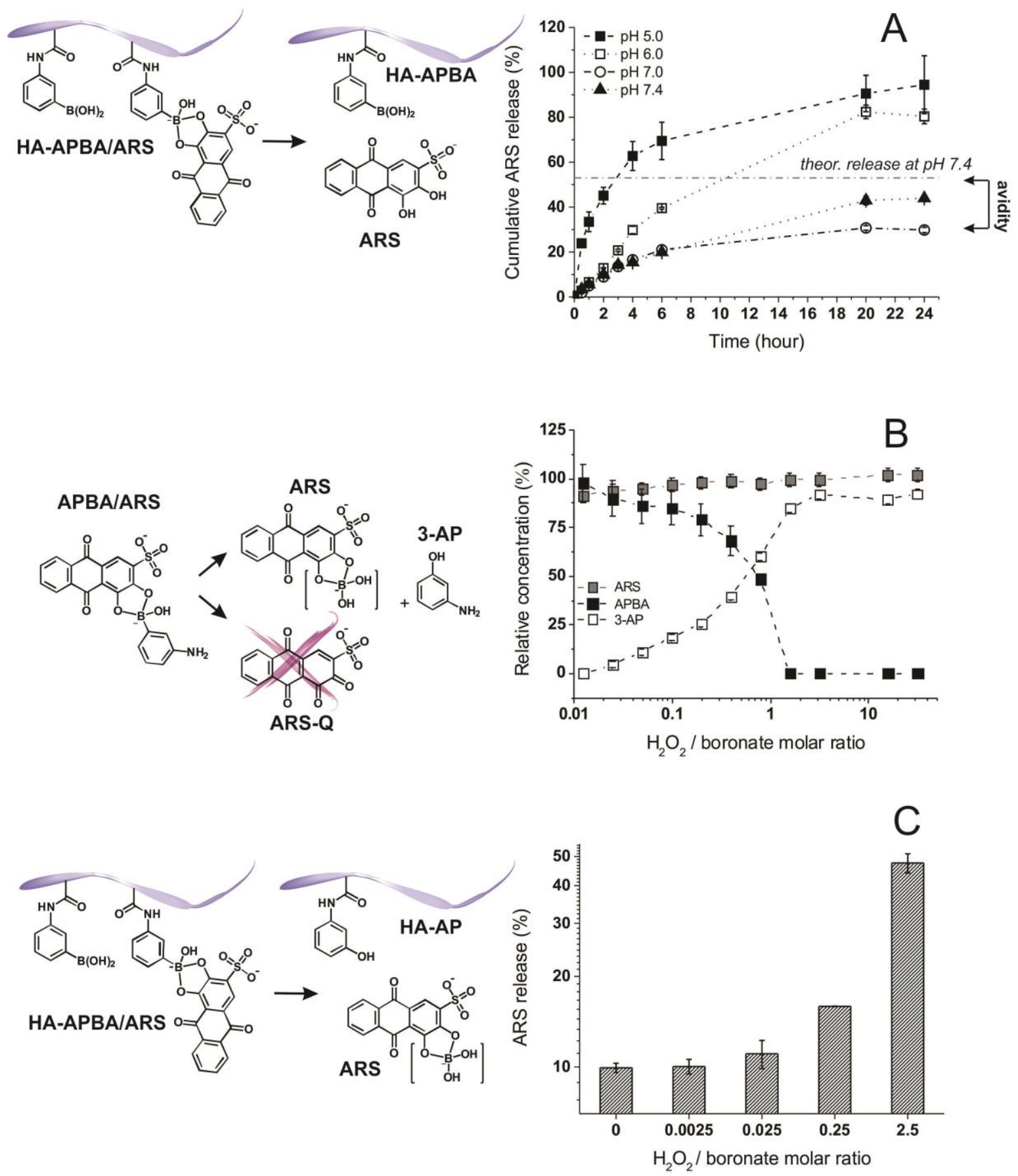

Figure 3. $A$ : An HA-APBA/ARS conjugate was prepared with $8.5 \mu \mathrm{mol}$ of boronic acid and $1.5 \mu \mathrm{mol}$ of ARS and was incubated at $37{ }^{\circ} \mathrm{C}$ in buffers at different $\mathrm{pH}$ values $(7.4,7.0,6.0$ and 5.0) in a dialysis bag. The release of free ARS in the dialysate was measured over 24 hours and expressed as relative to the overall amount. On the basis of the equilibrium constant presented in Table 1, under the experimental conditions used, $>50 \%$ of ARS should be released at neutral $\mathrm{pH}$; the fact that only about a half of it was actually released is attributed to the higher stability arising from the avidity of a structure with a large excess of uncomplexed boronates. B: The APBA/ARS conjugate was incubated for 2 hours at $37{ }^{\circ} \mathrm{C}$ in buffers $0.1 \mathrm{M}$ PBS buffer at $\mathrm{pH} 7.4$ with different amount of $\mathrm{H}_{2} \mathrm{O}_{2}$ and then $\mathrm{Na}_{2} \mathrm{SO}_{3}$ was added to quench the unreacted $\mathrm{H}_{2} \mathrm{O}_{2}$ and the samples were analysed through HPLC to measure the amount of ARS, APBA and 3-aminophenol (3-AP) produced. It is noteworthy to point out that during HLPC separation the complexes with ARS dissociated thus in the study we analysed separately ARS, APBA and 3-PA; moreover we did not discriminate between the ARS released in its free form or as ester with boric acid. $\boldsymbol{C}$ : The HA-APBA/ARS conjugate was incubated for 2 hours at $37{ }^{\circ} \mathrm{C}$ in buffers $0.1 \mathrm{M}$ PBS buffer at pH 7.4 with different amount of $\mathrm{H}_{2} \mathrm{O}_{2}$ and then centrifuged in centrifugal filters with nominal molecular weight limit of $3 \mathrm{kDa}$ to recover the unbound ARS. Again, we did not discriminate between the ARS released in its free form or as ester with boric acid. 


\section{CONCLUSION}

Here we have presented a successful proof of principle for the use of boronic/diol complexation for the purpose of reversible and responsive bioconjugation. In this demonstration, the use of HA as a model platform offers a plethora of benefits, including targeting.

We have thus compared the performance of a boronic acid-containing HA derivative to that of the low molecular weight APBA in the complexation to a library of diols. Instead of detrimentally affecting the equilibrium constants (e.g. because of steric hindrance or electrostatic repulsion between anionic boronic esters), the use of HA-APBA slightly increased (5-15\%) the average binding strength, which we attributed to the avidity of the polymeric structure.

It is noteworthy that we have adopted a modified analytical method for the evaluation of boronic/diols equilibria, which uses ARS as an absorbance reporter. In comparison to the more commonly fluorescence tests (based on ARS emission), this method is specifically advantageous to study concentrated and possibly heterogeneous samples, allowing for example to monitor this "click" reaction in a self-emulsifying system (Tween $20+$ quercetin) and during enzymatic kinetics, also performed on solubilized active principles (cyclodextrin + estradiol). Using this absorbance assay, we have also for the first time demonstrated that CYP2D6 is able to demethylate the monomethyl ether of dopamine (3-methoxytyramine). This finding could be important considering that one of the major drawbacks of Parkinson's disease therapies based on the use of catecholamine drugs or pro-drugs (e.g. L-DOPA) is the inactivation of the exogenous catecholamines through methylation (operated by catechol $O$-methyltransferase, COMT) ${ }^{62}$.

In the conclusive part of the study, we have then demonstrated that the boronic acid-bearing HA derivatives, allowed the responsive release of catechols in acidic or oxidative environment. Indirect evidence suggests that in the latter case the released catechols are not further oxidized to quinones possibly because they are release as boric acid complexes.

Since a slightly acidic $\mathrm{pH}$ and the presence of ROS are often associated to pathological states, we believe that this kind of HA bioconjugation could provide the means for a more efficient delivery due the combination of receptor $(\mathrm{CD} 44)$ targeting and triggered $\left(\mathrm{pH}\right.$ or $\left.\mathrm{H}_{2} \mathrm{O}_{2}\right)$ release.

\section{EXPERIMENTAL PROCEDURES}

The list of all reagents and the description of the synthetic procedures for all HA derivatives are reported in the Supporting Information, additional materials and methods.

If not otherwise stated, all solutions were prepared in 0.1 M PBS obtained by dissolving sodium dihydrogen orthophosphate dihydrate, disodium hydrogen orthophosphate dihydrate and sodium chloride, supplied by BDH (U.K.), in concentrations respectively of $2.3 \mathrm{~g} / \mathrm{L}, 11.8 \mathrm{~g} / \mathrm{L}$ and $9 \mathrm{~g} / \mathrm{L}$ in water purified in a Milli-Q system (Millipore, U.K.).

\section{Study of boronate-diol equilibria}

We have employed a BioTek Synergy 2 multi-mode microplate reader to record absorbance spectra (in the range $\lambda=400-800 \mathrm{~nm}$ ) and fluorescence readings (filters at $\lambda_{\text {exc }}=485 \pm 20 \mathrm{~nm}$ and $\lambda_{\text {em }}=$ $620 \pm 40 \mathrm{~nm}$ ); temperature was kept at $25^{\circ} \mathrm{C}$, except for the spectra of enzymatic reactions which were recorded at $37{ }^{\circ} \mathrm{C}$. All the spectra were corrected by subtracting the scattering component of the buffer solution using appropriate blanks.

In this analysis we have not differentiated between the equilibria leading to the formation of the trigonal or the tetragonal form of the diol-boronic esters. The binding constants provided for the diol-boronic equilibria are overall affinities at $\mathrm{pH}$ 7.4.

In this discussion we will identify ARS as $A$, the boronic acid partner as $B$, any competitive diol as $D$, the complex between $A$ and $B$ as $A B$ and the complex between $B$ and $D$ as $D B$. 


\section{1) Determination of ARS/boronic acids binding constants through fluorescence}

General conditions. The experimental design developed by Springsteen et al. ${ }^{30}$ was adapted to be performed in 96 well plates. Briefly, $125 \mu \mathrm{L}$ ARS solution $\left(1.8 \cdot 10^{-5} \mathrm{M}\right)$ were titrated with an equal volume a solution of PBA or APBA with concentrations ranging between $3.6 \cdot 10^{-3}$ and $1.8 \cdot 10^{-4} \mathrm{M}$. The plates were incubated $30 \mathrm{~min}$ in the plate reader at $25{ }^{\circ} \mathrm{C}$ and then the fluorescence intensities were recorded $\left(\lambda_{\text {exc }}=485 \pm 20 \mathrm{~nm}\right.$ and $\left.\lambda_{\mathrm{em}}=620 \pm 40 \mathrm{~nm}\right)$.

Analytical method used for the calculation of binding constants. The binding of ARS to PBA and APBA can be studied by recording the increase in fluorescence intensity of an ARS solution upon addition of the boronic acids, a method pioneered by $\mathrm{Wang}^{40}$. Fluorescence data were fitted according to the Benesi-Hildebrand method which can be used to measure the association constant $\left(K_{e q}\right)$ of a reaction when two species are in equilibrium with their one-to-one complex ${ }^{63}$. The mathematical approach is based on the assumption that when either one of the reactants is present in molar amount higher than 10 equivalents over the other reactant, its concentration can be considered constant. Under these conditions a set of data relating the recorded changes in fluorescence intensity $\left(\Delta I_{f}\right)$ at different initial concentrations of the boronic acid containing compound $\left(C_{B}\right)$ can be fitted according to the following equation:

$\frac{1}{\Delta I_{f}}=\left(\Delta k p_{0} C_{A} K_{e q}\right)^{-1} \cdot \frac{1}{C_{B}}+\left(\Delta k p_{0} C_{A}\right)^{-1}$

Where $C_{A}$ is the total concentration of ARS, and $\Delta k p_{0}$ is a constant derived from the quantum yield and instrumental parameters. Thus by plotting $1 / \Delta I_{f} v s 1 / C_{B}$, it is possible to obtain $K_{e q}$ dividing the intercept by the slope of the fitted line.

\section{2) Determination of ARS/boronic acids binding constants through hypsochromic shifts}

General conditions. For binding experiments, $125 \mu \mathrm{L}$ of a solution of APBA or PBA at a concentration ranging from 0.00 to $4.05 \mathrm{mM}$ (at least 23 different concentrations were prepared) were mixed in each well of a 96 well plate with $125 \mu \mathrm{L}$ of a solution $0.30 \mathrm{mM}$ of ARS (final ARS concentration $=0.15 \mathrm{mM}$, total volume $=250 \mu \mathrm{L} /$ well). The plate was incubated $30 \mathrm{~min}$ in the plate reader at $25^{\circ} \mathrm{C}$ and then the absorbance readings were recorded between 400 and $800 \mathrm{~nm}$ (Figure 1A provides a picture of a typical plate during the assay).

Analytical methods used for the calculation of binding constants. When using boronic acids such as APBA or PBA $(B)$ that lack a significant absorption in the visible or near UV spectral region, the only absorbing species are ARS $(A)$ and the ARS-boronic ester $(A B)$. The spectra of ARS alone and of its complex, obtained from ARS in the presence of a large excess of boronic acid containing compound, can be accurately fitted with Gaussian models (see Supporting Information, Figure 2SIA), it is possible to recreate the absorption spectrum of any mixture of ARS with its boronic ester, expressing it as a linear combination of the spectra of the two pure substances (see Supporting Information, Figure 2SIB):

$A b s=x_{A} C_{A} \varepsilon_{1} e^{\left[\frac{-2\left(\lambda-\lambda_{\max 1)}\right)}{\omega_{1}}\right]^{2}}+\left(1-x_{A}\right) C_{A} \varepsilon_{2} e^{\left[\frac{-2\left(\lambda-\lambda_{\max 2}\right)}{\omega_{2}}\right]^{2}}$

where the absorbance $A b s$ depends on the molar concentrations of the two products (expressed as the molar fraction $x_{A}$ times the total concentration of ARS, $\left(C_{A}\right)$, and on parameters obtained from the spectra of the two pure products: $\lambda_{\max 1}$ and $\lambda_{\max 2}, \varepsilon_{1}$ and $\varepsilon_{2}, \omega_{1}$ and $\omega_{2}$, which are, respectively, the wavelengths of the maxima of the spectra of ARS and of its boronic ester, the corresponding extinction coefficients and parameters related to the band width. By plotting the wavelength of the absorbance maxima of these calculated spectra $v s x_{A}$ one obtains a sigmoidal graph (Figure 2, right). This graph allows one to relate the location of the maximum absorption for a given ARS/boronated compound mixture to the fraction of free ARS in that mixture $\left(x_{A}\right)$. By knowing $x_{A}$ as a function of the 
constant of the equilibrium between ARS and APBA or PBA $\left(K_{l}\right)$ and of the initial concentrations of the reactants, $C_{A}$ and $C_{B}$ :

$$
\begin{aligned}
& K_{1}=\frac{[A B]}{[A][B]}=\frac{[A B]}{\left(C_{A}-[A B]\right)\left(C_{B}-[A B]\right)} \\
& {[A B]=\frac{C_{A}+C_{B}+\frac{1}{K_{1}}-\sqrt{\left(C_{A}+C_{B}+\frac{1}{K_{1}}\right)^{2}-4 C_{A} C_{B}}}{2}} \\
& x_{A}=1-\frac{[A B]}{C_{A}}=1-\frac{C_{A}+C_{B}+\frac{1}{K_{1}}-\sqrt{\left(C_{A}+C_{B}+\frac{1}{K_{1}}\right)^{2}-4 C_{A} C_{B}}}{2 C_{A}}
\end{aligned}
$$

Using a fixed concentration $C_{A}(0.15 \mathrm{mM})$ and varying $C_{B}$ (between 0.00 and $2.03 \mathrm{mM}$ ) it is possible to obtain a set of $x_{A}$ values, where $x_{A}=f\left(C_{B}\right)$. Equation 5 can be edited as user defined function in a data analysis software (Origin 8.5.1), allowing to calculate $K_{l}$ as a fittable parameter.

\section{3) Determination of diol/boronic acid binding constants through competitive binding with ARS}

General conditions. For competitive binding experiments in each well of a 96 well plate $50 \mu \mathrm{L}$ of a $0.75 \mathrm{mM}$ ARS solution and $50 \mu \mathrm{L}$ of a $0.75 \mathrm{mM}$ APBA solution were mixed; the colour of the solution changed from red to orange. Separately, diol solutions with concentrations ranging between 0.13 and $250.00 \mathrm{mM}$ were prepared (corresponding to ABPA/diol molar ratios ranging from 1:0.5 to 1:1000). $150 \mu \mathrm{L}$ of each diol solution (final ARS and APBA concentration $=0.15 \mathrm{mM}$, total volume $=$ $250 \mu \mathrm{L} /$ well) were added, producing a clear orange to red chromatic change at high ABPA/diol molar ratios. The absorbance readings were then recorded as previously described.

The general procedure was modified for the following cases:

- Reactions involving veratrylamine and phloroglucinol: due to their limited solubility in water, the highest APBA/diol molar ratio was 1:100.

- Reactions involving pyrogallol: owing to the quick oxidation of this electron-rich polyol, TCEP was added to the diol stock solution in a molar ratio pyrogallol/TCEP 1:1.5. Due to acidity of TCEP, a few drops of $1 \mathrm{M} \mathrm{NaOH}$ were added to bring the $\mathrm{pH}$ back to 7.4 .

- Reaction involving ascorbic acid: due to the acidic nature of this diol, the $\mathrm{pH}$ of the final solution in $0.1 \mathrm{M}$ PBS was raised to 7.4 by adding few drops of $1 \mathrm{M} \mathrm{NaOH}$.

- Reaction involving quercetin: owing to the very poor solubility of quercetin in water environment, Tween 20 (a surfactant widely employed in bioassays and pharmaceutical formulations) was used. For quercetin concentrations up to $1 \mathrm{mM}$ a 1:1 Tween 20/quercetin molar ratio was sufficient to completely solubilise it in $0.1 \mathrm{M}$ PBS buffer, in fact quercetin UV-Vis absorbance reached a plateau and did not increase with larger amounts of surfactant. The highest concentration of Tween 20 showed to be limited by its ability to hamper the binding reaction: a maximum of $8 \% \mathrm{w} / \mathrm{w}$ of Tween 20 can be used without affecting the reaction kinetics (data not shown).

- Reactions involving polymeric species: The amount of polymer was calculated on the basis of its number average degree of functionalization. HA derivatives were dissolved and kept in solution for $12 \mathrm{~h}$ prior to the addition of any reagent. Finally, TCEP was added to the solutions when polymers functionalised with dopamine were involved (dopamine/TCEP molar ratio $=1: 1.5$ ) to prevent oxidation.

Calculation of binding constants. The gradual addition of a diol $(D)$ to an ARS boronic ester determines an increasing batochromic shift due to the production of free ARS. The corresponding competitive equilibrium $A B+D \rightleftharpoons D B+A$ is governed by a constant $K$ which can be expressed as the ratio of the two equilibrium constants for the formation of individual boronic esters, $A B$ and $D B$, but can also be expressed as a function of the concentration of free ARS as the only variable (see equations 6 and 7). 
$K_{\text {exc }}=\frac{[A][D B]}{[A B][D]}=\frac{[A][B]}{[A B]} \cdot \frac{[D B]}{[B][D]}=\frac{K_{\text {diol }}}{K_{A R S}}$

$K_{\text {exc }}=\frac{[A][D B]}{[A B][D]}=\frac{[A]\left(C_{B}-[A B]\right)}{\left(C_{A}-[A]\right)[D]}=\frac{[A]\left(C_{B}-C_{A}+[A]\right)}{\left(C_{A}-[A]\right)\left(C_{D}-C_{B}+\left(C_{A}-[A]\right)\right.}$

For each given amount of diol, one obtains a $\lambda_{\max }$ value from which it is then possible to calculate the fraction of free ARS ([A] $=x_{A} \cdot C_{A}$ ), as shown in the previous section. From each $C_{D}$ value is possible to obtain $K_{\text {exc }}$ and finally, its value multiplied by $K_{A R S}$ is the equilibrium constant of interest, $K_{\text {diol }}$. The values of $K_{\text {diol }}$ were averaged through a range of diol concentrations corresponding to ABPA/diol molar ratio from 1:0.5 to 1:1000.

4) Enzymatic Reactions

General conditions. Typical experiments were performed in 96 well plates at $37{ }^{\circ} \mathrm{C}$ sealed with the help of PCR plate adhesive seals to prevent evaporation. The plates were prepared by mixing ARS and APBA as previously $(50 \mu \mathrm{L}$ of a $0.75 \mathrm{mM}$ ARS solution and $50 \mu \mathrm{L}$ of a $0.75 \mathrm{mM}$ APBA solution). Then $100 \mu \mathrm{L}$ of diol were added followed by $50 \mu \mathrm{L}$ of the enzyme working solution. The diol and the enzyme working solutions were prepared as follows:

- Demethylation of 3-methoxytyramine: the cytochrome P450 variant 2D6 can remove the methyl group from 3-methoxytyramine producing dopamine. 3-methoxytyramine was solubilised in PBS at concentrations ranging from $0.19 \mathrm{mM}$ to $1.22 \mathrm{mM}$ (final APBA/3-methoxytyramine molar ratio of 1:0.5 to $1: 3.2$ ). The solution of CYP2D6 was prepared by diluting $1: 50$ a $500 \mathrm{pmol} / \mathrm{mL}$ solution of enzyme with a $8.3 \mathrm{mg} / \mathrm{mL}$ (10 mM on anhydrous basis) solution of NADPH in $0.1 \mathrm{M}$ PBS.

- Hydroxylation of estradiol: estradiol can bind to boronic acid only upon the introduction of a second alcoholic function; this reaction can be carried out by cytochrome P450 variant 1A2. Estradiol (0.9 $\mathrm{mg} / \mathrm{mL}, 3.38 \mathrm{mM}$ ) was solubilised in PBS by the addition of $\beta$-cyclodextrin sulfobutylether (7.3 $\mathrm{mg} / \mathrm{mL}, 1: 1$ molar ratio). This solution was diluted to obtain diol concentrations ranging from 0.08 to $3.38 \mathrm{mM}$ (final APBA/estradiol molar ratio of 1:0.1 to 1:4.5). The CYP1A2 solution was prepared by diluting 1:25 a $1000 \mathrm{pmol} / \mathrm{mL}$ solution of enzyme with a $10.0 \mathrm{mg} / \mathrm{mL}$ (12 $\mathrm{mM}$ on anhydrous basis) solution of NADPH in $0.1 \mathrm{M}$ PBS.

Analytical methods used for the calculation of binding constants. All enzymatic tests were based on the in situ production of a diol in the presence of the ARS/APBA complex. With increasing production of the catechol, the ARS UV-Vis band undergoes a time- and concentration-dependent batochromic shift. The dependence on time provides information about the kinetics of the enzymatic conversion; the dependence on the concentration of the precursor provides information about the binding constant of the diol. In this part of the study we have always assumed that the enzymatic conversion is the rate-determining step of the test, i.e. the competitive equilibrium is established in an 'instantaneous' fashion as soon as new diol is produced. This assumption is reasonable, because the diol-boronic equilibria are established in a matter of seconds, while tenths of minutes are required to obtain quantitative yields in diols. We have also assumed that complete substrate conversion was obtained when the batochromic shifts reached their asymptotic values; in this way it is possible to replace $C_{D}$ in equation 7 with the initial substrate concentration $\left(\left[\mathrm{S}_{0}\right]\right)$, therefore allowing the calculation of the diol-boronic equilibrium constant $K_{\text {diol }}$.

It is then possible (see Supporting Information, Section 3SI Additional information about enzymatic reaction experiments) to use $K_{\text {diol }}$ to express the substrate concentration ([S]) as a function of the molar fraction of free ARS $\left(x_{A}\right)$, which can be calculated from the batochromic shift; from the time dependence of $[\mathrm{S}]$ it is possible to calculate the initial rate of the enzymatic reaction. In order to reduce the experimental error, this was done by fitting the time-dependent data as an exponential decay $\left([S]=\left[S_{0}\right] \cdot e^{-k t}\right)$. The initial reaction rate $v$ was then plotted $v s\left[\mathrm{~S}_{0}\right]$ and fitted using the usual Michaelis-Menten relationship $v=\frac{v_{\max }[S]}{K_{M}+[S]}$ 


\section{pH-induced release}

Four $1 \mathrm{~mL}$ Spectra/Por ${ }^{\circledR}$ Float-A-Lyzer ${ }^{\circledR}(\mathrm{MWCO}=10 \mathrm{kDa})$ were filled with $1 \mathrm{~mL}$ of a solution containing $20 \mathrm{mg}$ of HA-APBA (corresponding to $8.5 \mu \mathrm{mol}$ of boronic acid) and $0.5 \mathrm{mg}$ of ARS (1.5 $\mu \mathrm{mol})$ in $0.1 \mathrm{M}$ phosphate buffer at $\mathrm{pH} 6.0,7.0,7.4$ and $0.1 \mathrm{M}$ acetate buffer at $\mathrm{pH} 5.0$ respectively. The Float-A-Lyzer ${ }^{\circledR}$ were then immersed in $19 \mathrm{~mL}$ of the same buffers and incubated at $37{ }^{\circ} \mathrm{C} .150$ $\mu \mathrm{L}$ aliquots were collected at different time points $(\mathrm{n}=3$ for each sample) and the fluorescence intensities were recorded in a 96 well plate (filters at $\lambda_{\text {exc }}=485 \pm 20 \mathrm{~nm}$ and $\lambda_{\text {em }}=620 \pm 40 \mathrm{~nm}$ ) and compared with a calibration curve of ARS in the same buffer to measure the amount of ARS released.

\section{$\mathrm{H}_{2} \mathrm{O}_{2}$-induced release}

A) Oxidation of APBA/ARS. 11 wells of a 96 well plate were filled each with $50 \mu \mathrm{L}$ of a $2.9 \mathrm{mM}$ solution of ARS followed by $50 \mu \mathrm{L}$ of a $2.9 \mathrm{mM}$ solution of APBA; after $1 \mathrm{~min} 50 \mu \mathrm{L}$ of hydrogen peroxide which concentrations ranging from $30 \mu \mathrm{M}$ to $150 \mathrm{mM}$ were added and the plate was incubated at $37{ }^{\circ} \mathrm{C}$ for 2 hours. Finally, $50 \mu \mathrm{L}$ of a $0.2 \mathrm{M} \mathrm{Na}_{2} \mathrm{SO}_{3}$ were added to quench the unreacted $\mathrm{H}_{2} \mathrm{O}_{2}$ and the samples were analysed through HPLC. All the solutions were prepared in $0.1 \mathrm{M}$ phosphate buffer at $\mathrm{pH}$ 7.4. Samples were analyzed via reverse phase HPLC on a Agilent 1100 series HPLC equipped with analytical ( $5 \mu \mathrm{m}$ particle size, $4.6 \times 150 \mathrm{~mm}$ ) Zorbax Eclipse XDB-C18 column and a Laserchrom S3210 UV/VIS detector set at $254 \mathrm{~nm}$. The analysis was performed at $1 \mathrm{mg} / \mathrm{mL}$ in a mixed eluent composed of $10 \mathrm{mM}$ phosphate buffer at $\mathrm{pH} 7.4$ and acetonitrile with the following gradients: from $10 \%$ to $30 \%$ acetonitrile, $\min 0-6 \mathrm{~min}$; from $30 \%$ to $80 \%$ acetonitrile, min $6-12$; from $80 \%$ to $10 \%$ acetonitrile, $\min 12$ to 15 .

B) Oxidation of HA-APBA/ARS $300 \mu \mathrm{L}$ of a $5.0 \mathrm{mM}$ ARS solution $(1.5 \mu \mathrm{mol})$ were added to $1.7 \mathrm{~mL}$ of a $10 \mathrm{mg} / \mathrm{mL}$ solution of HA-APBA (corresponding to $7.2 \mu \mathrm{mol}$ of boronic acid), both solutions in PBS at pH 7.4. $200 \mu \mathrm{L}$ aliquots of the mixture were placed in Amicon Ultra-0.5 Centrifugal Filters with $3 \mathrm{kDa}$ MWCO (Millipore) followed by $200 \mu \mathrm{L}$ of $0.0073,0.073,0.73$ and $7.3 \mathrm{mM} \mathrm{H}_{2} \mathrm{O}_{2}(0.01$, $0.1,1$ and 10 equivalents respect to $\mathrm{ARS}$ or $0.0025,0.25,0.25$ and 2.5 equivalents respect to boronates) in PBS. The samples were incubated for 2 hours at $37^{\circ} \mathrm{C}$, then free ARS was recovered via centrifugation (13,000 rpm for $30 \mathrm{~min})$ and analysed via the above described HPLC method.

\section{ASSOCIATED CONTENT}

Supporting Information is provided as a separate document

\section{AUTHOR INFORMATION}

\section{Corresponding Author}

*For N.T: E-mail: Nicola.tirelli@manchester.ac.uk

\section{ACKNOWLEDGMENTS}

The authors acknowledge financial support from the EU FP7 project UniVax (grant number 601738) and from the Marie Curie IAPP Replixcel (grant number 251420), and from the AstraZeneca/University of Manchester co-funding of the NorthWest Centre of Advanced Drug Delivery (NoWCADD). The authors are indebted to Novozymes for the donation of all HA samples used in this study and want also to thank Dr. Elita Montanari for the helpful discussions.

\section{ABBREVIATIONS}

ARS, alizarin red S; APBA, 3-aminophenylboronic acid hydrochloride; PBA, phenylboronic acid; DOP, dopamine hydrochloride; NADPH, $\beta$-nicotinamide adenine dinucleotide 2 '-phosphate reduced 
tetrasodium salt hydrate; CYP2D6, human cytochrome P450 2D6 yeast reductase; CYP1A2, recombinant human cytochrome P450 1A2; HA, hyaluronic acid; PEG, poly(ethylene glycol); PEGDOP, monomethoxy poly(ethylene glycol); RHAMM, hyaluronan-mediated motility receptor, GlcNAc, $N$-acetyl glucosamine; GlcA, glucuronic acid; ROS, reactive oxygen species.

\section{REFERENCES}

1. Hall, D. (2011) Boronic Acids Volume 2 Preparation and Applications in Organic Synthesis, Medicine and Materials Second Completely Revised Edition Preface, Boronic Acids, Vol 2: Preparation and Applications in Organic Synthesis, Medicine and Materials, 2nd Edition, $\mathrm{Xv}-\mathrm{Xvii}$.

2. $\quad$ Furikado, Y., Nagahata, T., Okamoto, T., Sugaya, T., Iwatsuki, S., Inamo, M., Takagi, H. D., Odani, A., and Ishihara, K. (2014) Universal Reaction Mechanism of Boronic Acids with Diols in Aqueous Solution: Kinetics and the Basic Concept of a Conditional Formation Constant, Chem-Eur J 20, 13194-13202.

3. Akgun, B., and Hall, D. G. (2016) Fast and Tight Boronate Formation for Click Bioorthogonal Conjugation, Angew Chem Int Ed Engl 55, 3909-3913.

4. Winblade, N. D., Nikolic, I. D., Hoffman, A. S., and Hubbell, J. A. (2000) Blocking adhesion to cell and tissue surfaces by the chemisorption of a poly-L-lysine-graft-(poly(ethylene glycol); phenylboronic acid) copolymer, Biomacromolecules 1, 523-533.

5. Winblade, N. D., Schmokel, H., Baumann, M., Hoffman, A. S., and Hubbell, J. A. (2002) Sterically blocking adhesion of cells to biological surfaces with a surface-active copolymer containing poly(ethylene glycol) and phenylboronic acid, J. Biomed. Mater. Res. 59, 618-631.

6. Striegler, S. (2003) Selective carbohydrate recognition by synthetic receptors in aqueous solution, Curr. Org. Chem. 7, 81-102.

7. Stolowitz, M. L., Ahlem, C., Hughes, K. A., Kaiser, R. J., Kesicki, E. A., Li, G., Lund, K. P., Torkelson, S. M., and Wiley, J. P. (2001) Phenylboronic acid-salicylhydroxamic acid bioconjugates. 1. A novel boronic acid complex for protein immobilization, Bioconjug Chem 12, 229-239.

8. Wiley, J. P., Hughes, K. A., Kaiser, R. J., Kesicki, E. A., Lund, K. P., and Stolowitz, M. L. (2001) Phenylboronic acid-salicylhydroxamic acid bioconjugates. 2. Polyvalent immobilization of protein ligands for affinity chromatography, Bioconjug Chem 12, 240-250.

9. Bapat, A. P., Roy, D., Ray, J. G., Savin, D. A., and Sumerlin, B. S. (2011) Dynamic-Covalent Macromolecular Stars with Boronic Ester Linkages, J. Am. Chem. Soc. 133, 19832-19838.

10. Li, Y., Xiao, W., Xiao, K., Berti, L., Luo, J., Tseng, H. P., Fung, G., and Lam, K. S. (2012) Well-defined, reversible boronate crosslinked nanocarriers for targeted drug delivery in response to acidic pH values and cis-diols, Angew Chem Int Ed Engl 51, 2864-2869.

11. Deng, C. C., Brooks, W. L. A., Abboud, K. A., and Sumerlin, B. S. (2015) Boronic AcidBased Hydrogels Undergo Self-Healing at Neutral and Acidic pH, ACS Macro Lett. 4, 220224.

12. Brooks, W. L. A., and Sumerlin, B. S. (2016) Synthesis and Applications of Boronic AcidContaining Polymers: From Materials to Medicine, Chem. Rev. 116, 1375-1397.

13. Ward, P. D., Thibeault, S. L., and Gray, S. D. (2002) Hyaluronic acid: Its role in voice, $J$ Voice 16, 303-309.

14. Fraser, J. R. E., Laurent, T. C., and Laurent, U. B. G. (1997) Hyaluronan: Its nature, distribution, functions and turnover, J. Intern. Med. 242, 27-33.

15. Adam, N., and Ghosh, P. (2001) Hyaluronan molecular weight and polydispersity in some commercial intra-articular injectable preparations and in synovial fluid, Inflamm. Res 50, 294299.

16. Toole, B. P. (2000) Hyaluronan is not just a goo!, J Clin Invest 106, 335-336.

17. Stern, R. (2003) Devising a pathway for hyaluronan catabolism: are we there yet?, Glycobiology 13, 105R-115R.

18. Brandt, F. S., and Cazzaniga, A. (2008) Hyaluronic acid gel fillers in the management of facial aging, Clin Interv Aging 3, 153-159. 
19. Fakhari, A., and Berkland, C. (2013) Applications and emerging trends of hyaluronic acid in tissue engineering, as a dermal filler and in osteoarthritis treatment, Acta Biomater. 9, 70817092.

20. Zhang, H., Huang, S., Yang, X., and Zhai, G. (2014) Current research on hyaluronic aciddrug bioconjugates, Eur J Med Chem 86, 310-317.

21. Mero, A., and Campisi, M. (2014) Hyaluronic Acid Bioconjugates for the Delivery of Bioactive Molecules, Polymers 6, 346-369.

22. Lesley, J., Hyman, R., English, N., Catterall, J. B., and Turner, G. A. (1997) CD44 in inflammation and metastasis, Glycoconjugate J 14, 611-622.

23. Hiscox, S., Baruha, B., Smith, C., Bellerby, R., Goddard, L., Jordan, N., Poghosyan, Z., Nicholson, R. I., Barrett-Lee, P., and Gee, J. (2012) Overexpression of CD44 accompanies acquired tamoxifen resistance in MCF7 cells and augments their sensitivity to the stromal factors, heregulin and hyaluronan, Bmc Cancer 12.

24. Bhatavdekar, J. M., Patel, D. D., Chikhlikar, P. R., Trivedi, T. I., Gosalia, N. M., Ghosh, N., Shah, N. G., Vora, H. H., and Suthar, T. P. (1998) Overexpression of CD44: A useful independent predictor of prognosis in patients with colorectal carcinomas, Ann Surg Oncol 5, 495-501.

25. Doventas, A., Bilici, A., Demirelli, F., Ersoy, G., Turna, H., and Doventas, Y. (2012) Prognostic Significance of CD44 and c-erb-B2 Protein Overexpression in Patients with Gastric Cancer, Hepato-Gastroenterol 59, 2196-2201.

26. Klingbeil, P., Natrajan, R., Everitt, G., Vatcheva, R., Marchio, C., Palacios, J., Buerger, H., Reis, J. S., and Isacke, C. M. (2010) CD44 is overexpressed in basal-like breast cancers but is not a driver of 11p13 amplification, Breast Cancer Res $\operatorname{Tr} 120,95-109$.

27. Gee, K., Kryworuchko, M., and Kumar, A. (2004) Recent advances in the regulation of CD44 expression and its role in inflammation and autoimmune diseases, Arch Immunol Ther Ex 52, 13-26.

28. Haynes, B. F., Hale, L. P., Patton, K. L., Martin, M. E., and McCallum, R. M. (1991) Measurement of an adhesion molecule as an indicator of inflammatory disease activity. Upregulation of the receptor for hyaluronate (CD44) in rheumatoid arthritis, Arthritis Rheum 34, 1434-1443.

29. Montanari, E., Gennari, A., Pelliccia, M., Gourmel, C., Lallana, E., Matricardi, P., McBain, A. J., and Tirelli, N. (2016) Hyaluronan/Tannic Acid Nanoparticles Via Catechol/Boronate Complexation as a Smart Antibacterial System, Macromol Biosci.

30. Springsteen, G., and Wang, B. H. (2002) A detailed examination of boronic acid-diol complexation, Tetrahedron 58, 5291-5300.

31. Su, J., Chen, F., Cryns, V. L., and Messersmith, P. B. (2011) Catechol Polymers for pHResponsive, Targeted Drug Delivery to Cancer Cells, J. Am. Chem. Soc. 133, 11850-11853.

32. Yang, B., Lv, Y., Zhu, J. Y., Han, Y. T., Jia, H. Z., Chen, W. H., Feng, J., Zhang, X. Z., and Zhuo, R. X. (2014) A pH-responsive drug nanovehicle constructed by reversible attachment of cholesterol to PEGylated poly(l-lysine) via catechol-boronic acid ester formation, Acta Biomater 10, 3686-3695.

33. Kabalka, G. W., and Hedgecock, H. C. (1975) Mild and Convenient Oxidation Procedure for Conversion of Organoboranes to Corresponding Alcohols, J Org Chem 40, 1776-1779.

34. Kuivila, H. G. (1954) Electrophilic Displacement Reactions .3. Kinetics of the Reaction between Hydrogen Peroxide and Benzeneboronic Acid, J. Am. Chem. Soc. 76, 870-874.

35. Kuivila, H. G., and Williams, R. M. (1954) Electrophilic Displacement Reactions .5. Kinetics of the Iodinolysis of Para-Methoxybenzeneboronic Acid, J. Am. Chem. Soc. 76, 2679-2682.

36. Letsinger, R. L., and Skoog, I. H. (1955) Organoboron Compounds .6. Preparation of a Heterocyclic Organoboron Compound, J. Am. Chem. Soc. 77, 5176-5177.

37. de Gracia Lux, C., Joshi-Barr, S., Nguyen, T., Mahmoud, E., Schopf, E., Fomina, N., and Almutairi, A. (2012) Biocompatible polymeric nanoparticles degrade and release cargo in response to biologically relevant levels of hydrogen peroxide, J Am Chem Soc 134, 1575815764.

38. Scarano, W., Lu, H. X., and Stenzel, M. H. (2014) Boronic acid ester with dopamine as a tool for bioconjugation and for visualization of cell apoptosis, Chem Commun 50, 6390-6393. 
39. Martinez-Aguirre, M. A., Villamil-Ramos, R., Guerrero-Alvarez, J. A., and Yatsimirsky, A. K. (2013) Substituent effects and $\mathrm{pH}$ profiles for stability constants of arylboronic acid diol esters, $J$ Org Chem 78, 4674-4684.

40. Springsteen, G., and Wang, B. H. (2001) Alizarin Red S. as a general optical reporter for studying the binding of boronic acids with carbohydrates, Chem Commun, 1608-1609.

41. Kuntz, I. D., Gasparro, F. P., Johnston, M. D., and Taylor, R. P. (1968) Molecular Interactions and Benesi-Hildebrand Equation, J. Am. Chem. Soc. 90, 4778-\&.

42. Stern, R., and Jedrzejas, M. J. (2006) Hyaluronidases: Their genomics, structures, and mechanisms of action, Chem. Rev. 106, 818-839.

43. Zhong, S. P., Campoccia, D., Doherty, P. J., Williams, R. L., Benedetti, L., and Williams, D. F. (1994) Biodegradation of Hyaluronic-Acid Derivatives by Hyaluronidase, Biomaterials 15, 359-365.

44. Campoccia, D., Doherty, P., Radice, M., Brun, P., Abatangelo, G., and Williams, D. F. (1998) Semisynthetic resorbable materials from hyaluronan esterification, Biomaterials 19, 21012127.

45. Andersson, T., Miners, J. O., Veronese, M. E., Tassaneeyakul, W., Meyer, U. A., and Birkett, D. J. (1993) Identification of human liver Cytochrome-P450 Isoforms mediating Omeprazole metabolism, Br. J. Clin. Pharmacol. 36, 521-530.

46. Penner, N. A., and Nesterenko, P. N. (2000) Simultaneous determination of dihydroxybenzenes, aminophenols and phenylenediamines in hair dyes by high-performance liquid chromatography on hypercross-linked polystyrene, Analyst 125, 1249-1254.

47. Nasri, Z., and Shams, E. (2009) Application of silica gel as an effective modifier for the voltammetric determination of dopamine in the presence of ascorbic acid and uric acid, Electrochim. Acta 54, 7416-7421.

48. Higuchi, T., and Schroeter, L. C. (1960) Kinetics and Mechanism of Formation of Sulfonate from Epinephrine and Bisulfite, J. Am. Chem. Soc. 82, 1904-1907.

49. Nikolajsen, R. P. H., Hansen, A. M., and Bro, R. (2001) Attempt to separate the fluorescence spectra of adrenaline and noradrenaline using chemometrics, Luminescence 16, 91-101.

50. Deeble, D. J., Parsons, B. J., Phillips, G. O., Schuchmann, H. P., and Vonsonntag, C. (1988) Superoxide Radical Reactions in Aqueous-Solutions of Pyrogallol and Normal-Propyl Gallate - the Involvement of Phenoxyl Radicals - a Pulse-Radiolysis Study, Int. J. Radiat. Biol. 54, 179-193.

51. Ye, J. N., Zhao, X. W., Sun, Q. X., and Fang, Y. Z. (1998) Capillary electrophoresis as a method for determining dissociation constants of aldohexose isomers, Mikrochim. Acta 128, 119-123.

52. Ross, M. A. (1994) Determination of Ascorbic-Acid and Uric-Acid in Plasma by HighPerformance Liquid-Chromatography, J. Chromatogr. B-Biomed. Appl. 657, 197-200.

53. Yan, J., Springsteen, G., Deeter, S., and Wang, B. H. (2004) The relationship among $\mathrm{pK}(\mathrm{a}), \mathrm{pH}$, and binding constants in the interactions between boronic acids and diols - it is not as simple as it appears, Tetrahedron 60, 11205-11209.

54. Subrahmanyam, V., Renwick, A. B., Walters, D. G., Young, P. J., Price, R. J., Tonelli, A. P., and Lake, B. G. (2001) Identification of cytochrome P-450 isoforms responsible for cistramadol metabolism in human liver microsomes, Drug Metab. Dispos. 29, 1146-1155.

55. Zhu, B. T., and Conney, A. H. (1998) Functional role of estrogen metabolism in target cells: review and perspectives, Carcinogenesis 19, 1-27.

56. Hiroi, T., Imaoka, S., and Funae, Y. (1998) Dopamine formation from tyramine by CYP2D6, Biochem. Biophys. Res. Commun. 249, 838-843.

57. Yamazaki, H., Shaw, P. M., Guengerich, F. P., and Shimada, T. (1998) Roles of cytochromes P450 1A2 and 3A4 in the oxidation of estradiol and estrone in human liver microsomes, Chem. Res. Toxicol. 11, 659-665.

58. Zhou, S. F. (2009) Polymorphism of Human Cytochrome P450 2D6 and Its Clinical Significance Part I, Clin Pharmacokinet 48, 689-723.

59. Salole, E. G. (1987) The physicochemical properties of estradiol, J. Pharm. Biomed. Anal. 5, 635-648. 
60. Bull, S. D., Davidson, M. G., Van den Elsen, J. M. H., Fossey, J. S., Jenkins, A. T. A., Jiang, Y. B., Kubo, Y., Marken, F., Sakurai, K., Zhao, J. Z., et al. (2013) Exploiting the Reversible Covalent Bonding of Boronic Acids: Recognition, Sensing, and Assembly, Acc. Chem. Res 46, 312-326.

61. Nishiyabu, R., Kubo, Y., James, T. D., and Fossey, J. S. (2011) Boronic acid building blocks: tools for sensing and separation, Chem Commun 47, 1106-1123.

62. BenMoyal-Segal, L., and Soreq, H. (2006) Gene-environment interactions in sporadic Parkinson's disease, J. Neurochem. 97, 1740-1755.

63. Benesi, H. A., and Hildebrand, J. H. (1949) A Spectrophotometric Investigation of the Interaction of Iodine with Aromatic Hydrocarbons, J. Am. Chem. Soc. 71, 2703-2707. 